ARTIGO

\title{
De quem é a responsabilidade? Uma análise das perspectivas para a lei de responsabilidade educacional prevista no Plano Nacional de Educação
}

Danilo Trombetta Neves a Cristiano Amaral Garboggini Di Giorgi ${ }^{b}$

\section{Resumo}

A promoção de um padrão mínimo de qualidade para a Educação Básica pública norteará a elaboração da legislação sobre responsabilidade educacional, contemplando o modo de organizar, estruturar e disciplinar a administração pública, voltada à obtenção da eficiência na prestação do serviço público. $\mathrm{O}$ Plano Nacional de Educação (PNE) não vincula seu financiamento ao atingimento de metas de desempenho, em virtude da própria fundamentalidade do direito à Educação, não permitindo retrocessos legislativos ou fático-orçamentários. Portanto, a possível Lei de Responsabilidade Educacional (LRE) deve ater-se, precipuamente, a articular elementos políticos, financeiros, administrativos, tecnológicos, organizacionais e pedagógicos para a promoção da Educação Básica pública com padrão mínimo de qualidade, afastando-se da ênfase punitiva como vetor de transformação.

Palavras-chave: Política Educacional. Lei de Responsabilidade Educacional. Plano Nacional de Educação.

\section{Introdução}

Passados 30 anos de vigência da Constituição Cidadã de 1988, é possível notar que um de seus pilares de sustentação está ainda em construção: a promoção de uma Educação Básica pública de qualidade. É inegável que o desenvolvimento

\footnotetext{
a Universidade do Oeste Paulista, Presidente Prudente, SP, Brasil.

b Universidade do Oeste Paulista, Presidente Prudente, SP, Brasil. 
de uma nação passa pelo progresso de seus cidadãos no campo educacional. Historicamente, contextos nacionais foram alterados, sobretudo, por meio da elevação do nível educacional e cultural.

Em consonância com alguns expertos, verifica-se, sim, um avanço na oferta de vagas e na democratização da escola pública. Contudo, esse avanço não veio acompanhado da devida política e estrutura para proporcionar aos seus beneficiários um padrão de qualidade razoável, motivo pelo qual perduram as discussões, inserindo-se, nesse contexto, o tema da responsabilidade educacional.

Dentro de uma perspectiva histórica, Oliveira e Araújo (2005) apontam três significados distintos de qualidade: o primeiro, condicionado pela oferta limitada de oportunidades de escolarização; o segundo, dirigido à ideia de fluxo, definido como número de alunos que progridem ou não dentro do sistema de Ensino e, finalmente, a ideia de qualidade associada à aferição de desempenho mediante testes em larga escala.

O atual Plano Nacional de Educação (PNE), Lei no 13.005, de 25 de junho de 2014 (BRASIL, 2014), previu, na estratégia 20.11 de seu anexo, a aprovação, no prazo de um ano, uma "Lei de Responsabilidade Educacional, assegurando padrão de qualidade na Educação Básica, em cada sistema e rede de Ensino, aferida pelo processo de metas de qualidade por institutos oficiais de avaliação educacional". Dessa forma, percebe-se que o objetivo do estabelecimento dessa lei é a conquista de um padrão de qualidade na Educação Básica em cada sistema e rede de Ensino.

Em acréscimo, outros projetos legislativos orbitaram o tema da qualidade da Educação, notadamente os Projetos de Lei sobre a Responsabilidade Educacional propriamente dita.

Diante disso, para se avançar na qualidade da Educação, busca-se que as políticas públicas preservem as conquistas normativas (constitucionais e infraconstitucionais), razão pela qual toda atividade legislativa se norteia pelo conjunto normativo disponível, em especial, e de modo bem atual, pelas diretrizes do PNE.

Assim, ao se pensar nas implicações do PNE na promoção da Educação e na responsabilidade educacional, emergem quatro temas: qualidade e responsabilidade no campo da Educação; promoção da Educação; avaliação, metas de desempenho e financiamento e responsabilização dos agentes públicos. 


\section{Qualidade e responsabilidade no campo da Educação}

Partindo da Constituição Federal do Brasil (BRASIL, 1988, art. 205), nota-se que a qualidade da Educação se relaciona com o pleno desenvolvimento da pessoa, seu preparo para o exercício da cidadania e sua qualificação para o trabalho.

Na concepção de Paro (2007, p. 33), a função da escola sintetiza-se na formação do cidadão em sua dupla dimensão: individual e social. "Enquanto a primeira dimensão exige a assunção do homem como sujeito (autor, portador autônomo de vontade), a segunda assume a necessidade de convivência livre (entendida a liberdade como construção histórica) entre os sujeitos individuais e coletivos".

Discorrendo sobre a qualidade da Educação, acrescenta:

A qualidade da Educação oferecida deve referir-se, portanto, à formação da personalidade do educando em sua integralidade, não apenas à aquisição de conhecimentos em seu sentido tradicional. Certamente, não se trata de voltar-se contra os conteúdos das disciplinas que usualmente compõem os currículos, e sim de valorizar esses conteúdos, mas fazê-lo de acordo com sua contribuição integral, superando a função meramente "credencialista", na qual se tem pautado o Ensino Básico. Essa superação envolve o cuidado não apenas com o conteúdo (entendido em seu sentido usual de rol de conhecimentos e informações contidos nas disciplinas e programas), que deve incluir novos elementos promotores da Educação integral, mas também com a forma democrática de ensinar, por meio da qual se promove a condição de sujeito do educando, forma essa que, como tal, reveste-se de notável potencial formador de personalidades democráticas e que, assim, deve ser entendida como conteúdo da Educação (PARO, 2007, p. 34, grifo do autor).

Essa formulação ancora-se no fato de que a Educação é atualização histórico-cultural, supondo que os componentes de formação que propicia ao ser humano são algo muito mais rico e mais complexo do que a simples transmissão de informações: "Como mediação para a apropriação histórica da herança cultural a que supostamente tem direito os cidadãos, o fim último da Educação é favorecer uma vida com maior satisfação individual e melhor convivência social" (PARO, 2007, p. 21).

A discussão sobre a qualidade da Educação pública é marcada por posições antagônicas. A primeira posição pode ser descrita como civil democrática, por considerar a Educação, em geral, e a escolar, em particular, como processo 
de formação cidadã, visando ao exercício de direitos e obrigações típicos da democracia. Já a segunda posição é descrita como produtivista, por conceber a Educação escolar como simples preparação dos indivíduos para o ingresso, da melhor forma possível, na divisão social do trabalho. Educar consistiria em instruir e em desenvolver faculdades que habilitem o educando a integrar o mercado de trabalho o mais vantajosamente possível (LEITE; DI GIORGI, 1995).

Portanto, ao se pensar numa Lei de Responsabilidade Educacional (LRE), discutese o modelo ou tipo de qualidade educacional almejado; sendo assim, conforme demonstrado no referencial teórico, para a presente argumentação, adota-se a concepção civil democrática.

Com relação à responsabilidade, contribui Cury (2012, p. 3, grifo nosso) ao conceituar:

Por responsabilidade deve-se entender a obrigação que pesa sobre um sujeito em satisfazer uma prestação (social) que lhe é positivamente atribuída. Cumprir encargos, desempenhar atribuições confiadas a um administrador público é uma obrigação que não sendo fielmente cumprida responde, e (é responsabilizado) por eventuais omissões ou irregularidades.

Para Freitas (2011), duas concepções de responsabilização estão presentes e permeiam os embates. A primeira concepção está voltada para a "responsabilização de cima para baixo, baseada em leis que regulam não só idoneidade das relações financeiras, mas que incluem o controle de metas na escola". Nessa perspectiva, a lei de responsabilidade educacional criará condições para que os estados possam produzir legislação específica que fiscalize a obtenção de metas pelas escolas e permita sua associação a consequências (bônus ou demissão, privatização etc.). A segunda concepção está baseada na responsabilização “[...] participativa e democrática, ancorada no envolvimento de todos os responsáveis pela questão educativa na escola e nos sistemas educacionais. Para esta visão, a lei de responsabilidade educacional não deveria tratar do controle de metas acadêmicas" (FREITAS, 2011, s. p.).

Ao aprofundar sua argumentação, destaca:

A primeira formulação de responsabilização é uma transferência de responsabilidade para a escola, associada a premiações ou punições. Muito conveniente para os governos em todos os níveis. A segunda 
propõe uma responsabilização que exija de cada ator do sistema educacional sua parcela de responsabilidade, em um processo de negociação liberal em que a escola, protagonista do processo, tem suas responsabilidades delimitadas, assim como também os responsáveis pela administração do sistema - em especial, na questão da criação das condições adequadas de funcionamento do sistema educacional carreira, salários, infraestrutura, capacidade administrativa, etc. Nesse caso, o indicador de sucesso não é apenas o desempenho do aluno em um teste padronizado. Este é apenas um dos componentes da avaliação do desempenho da escola e, além disso, há indicadores para os gestores cumprirem também (carreira, tamanho de turma, piso salarial, recursos, infraestrutura, custo-aluno, etc.) (FREITAS, 2011, s. p.).

A relevância do direito fundamental à Educação, frente ou em concorrência com outros direitos sociais, não afasta a Educação pública da categoria de serviço público, inclusive para que se possa, sobriamente, aplicar-lhe novas propostas condizentes com sua envergadura, direitos, responsabilidades e também prerrogativas de seus agentes (políticos ou profissionais da Educação em geral), genericamente considerados.

Nesse compasso, uma possível LRE necessitará alinhar-se com todo o conjunto de direitos e de garantias públicas, não apenas especificamente do campo educacional, mas em total consonância com os direitos fundamentais, em busca de uma equalização de políticas e de ações que, acima de tudo, estejam voltadas para a promoção da qualidade da Educação Básica pública. O PNE traz em seu bojo importantes delineamentos.

\section{Promoção da Educação}

Para a promoção da Educação, a Lei no 13.005/2014 (BRASIL, 2014), que instituiu o PNE, já nas suas diretrizes, prevê, no inciso VIII do artigo $1^{\circ}$, o estabelecimento de meta de aplicação de recursos públicos em Educação como proporção do Produto Interno Bruto (PIB), que assegure atendimento às necessidades de expansão, com padrão de qualidade e de equidade.

Do mesmo modo, o artigo 10 do PNE (BRASIL, 2014) é diretivo ao informar que o plano plurianual, as diretrizes orçamentárias e os orçamentos anuais da União, dos Estados, do Distrito Federal e dos Municípios serão formulados de maneira a assegurar a consignação de dotações orçamentárias compatíveis com as diretrizes, metas e estratégias do PNE e com os respectivos planos de Educação, a fim de viabilizar sua plena execução. 
Tais medidas foram anteriormente preanunciadas por expertos do assunto. Nesse ponto, é conveniente mencionar a preocupação de Gomes (2008), ao trazer os Fundamentos de uma LRE, enfatizando a imprescindível reforma do Estado, com adoção de condições simples, palpáveis e visíveis, para que toda escola funcione:

1 - Profissionais titulados, desde que os títulos representem competência;

2 - Instalações e equipamentos mínimos, em bom estado de conservação e funcionamento;

3-Materiais indispensáveis: livros, inclusive didáticos, e material escolar;

4-Cumprimento de tempo letivo necessário para a aprendizagem. (p. 11).

O segundo aspecto a ser considerado reporta-se ao Princípio Constitucional da Eficiência aplicado à administração pública. No ponto, calha a lição da doutrinadora administrativista Di Pietro (2009) ao distinguir o modo de atuação do agente público, do qual se espera o melhor desempenho de suas atribuições para lograr os melhores resultados, do modo de organizar, de estruturar e de disciplinar a administração pública, também com o objetivo de alcançar os melhores resultados na prestação do serviço público.

Como já mencionado, a administração pública, enquanto poder público em toda a sua amplitude, necessita prover a organização e a estrutura elementar para a garantia de um padrão mínimo de qualidade da Educação Básica pública. Isso implica a adoção de medidas de impacto na política, na administração, no orçamento, na comunicação e em setores correlacionados aos entes federados no que tange ao serviço público denominado Educação.

Nesse sentido, a Meta 7 do PNE visa fomentar a qualidade da Educação Básica em todas as etapas e modalidades, com melhoria do fluxo escolar e da aprendizagem.

Historicizando o tema da responsabilidade educacional, registre-se que tramitou na Câmara dos Deputados Federais o Projeto de Lei n ${ }^{\circ} 7.420$, de 9 de agosto de 2006 (BRASIL, 2006), de autoria da professora e ex-deputada federal Raquel Teixeira (PSDB/GO), em torno do qual foram apensados outros 17 projetos (Projetos de Lei $\mathrm{n}^{\mathrm{o}} 247 / 2007, \mathrm{n}^{\mathrm{o}}$ 600/2007; $\mathrm{n}^{\mathrm{o}} 1.256 / 2007 ; \mathrm{n}^{\circ} 1.680 / 2007 ; \mathrm{n}^{\circ} 4.886 / 2009$; $\mathrm{n}^{\mathrm{o}} 8.039 / 2010 ; \mathrm{n}^{\mathrm{o}} 8.042 / 2010 ; \mathrm{n}^{\mathrm{o}} 413 / 2011 ; \mathrm{n}^{\circ} 450 / 2011 ; \mathrm{n}^{\mathrm{o}} 1.747 / 2011 ; \mathrm{n}^{\mathrm{o}} 1.915 / 2011$; $\mathrm{n}^{\mathrm{o}} 2.417 / 2011 ; \mathrm{n}^{\mathrm{o}} 2.604 / 2011 ; \mathrm{n}^{\mathrm{o}} 3.066 / 2011 ; \mathrm{n}^{\mathrm{o}} 5.519 / 2013 ; \mathrm{n}^{\mathrm{o}} 5.647 / 2013 \mathrm{e}$ $\left.\mathrm{n}^{\mathrm{o}} 6.137 / 2013\right)$. O projeto principal e apenso tramitou pela Coordenação de Comissões 
Permanentes (CCP), pela Comissão de Educação e Cultura (CEC), pela Comissão de Finanças e Tributação (CFT) e pelo Plenário, todos da Câmara dos Deputados Federais. Por deliberação do Plenário, na sessão do dia 13 de outubro de 2011, foi constituída uma Comissão Especial destinada a dar parecer sobre o Projeto de Lei $\mathrm{n}^{\circ}$ 7.420/2006 (BRASIL,2006) e demais projetos apensados. Designou-se o deputado federal Raul Henry (PMDB/PE) como relator.

Os Projetos de Lei $\mathrm{n}^{\circ} 7.420 / 2006$ (BRASIL, 2006), $\mathrm{n}^{\circ}$ 1.680/2007 (BRASIL, 2007), $n^{\circ} 413 / 2011$ (BRASIL, 2011a), ${ }^{\circ}$ 450/2011 (BRASIL, 2011b), assim como o projeto substitutivo do relator da Comissão Especial e deputado federal Raul Henry, apresentaram medidas voltadas para a promoção da Educação Básica pública, contemplando formação e plano de carreira do magistério público, jornada de trabalho, Plano de Educação, infraestrutura escolar, gestão democrática e avaliação do desempenho dos profissionais do magistério.

Do embate legislativo, percebe-se que a promoção e a responsabilidade pelo padrão mínimo de qualidade não recairão, de maneira exclusiva, sobre aqueles agentes públicos reconhecidamente caracterizados como profissionais da Educação que atuam na ponta do organograma/sistema.

É oportuno destacar o papel do Estado, representado pela autoridade política, como um ente estruturante e incumbido de prover condições para a materialização dos direitos. Nesse sentido, Cury (2012, p. 3, grifo do autor) afirma:

Esse poder jurisdicional de uma autoridade pública existe para traduzir do melhor modo o que diz o termo autoridade. Etimologicamente, tal termo procede do verbo latino augere e quer dizer crescer. A autoridade pública está investida de poder a fim de gerar condições para que as pessoas, na qualidade de cidadãos, cresçam de modo a desenvolverem suas personalidades, participarem ativamente da sociedade em que vivem e serem profissionalmente inseridos no mundo do trabalho.

Merece menção, nesse ponto, a constatação de dados estatísticos relacionados com o rendimento escolar e a infraestrutura e o funcionamento das escolas, conforme apresentam Diniz, Fontanive e Klein (2013, p. 550):

Como tem sido observado nas diferentes edições do Saeb/Prova Brasil, em geral, a média do desempenho dos alunos decresce daqueles que estudam em escolas com ótimas condições para aqueles em escolas com péssimas condições de infraestrutura e funcionamento. 
Verifica-se, aqui, que não se está afastando a atribuição e a responsabilidade quanto ao modo de atuação do agente público profissional da Educação. Contudo, os dois aspectos sopesados influem diretamente na promoção da Educação com padrão mínimo de qualidade.

Em suma, a questão da qualidade da Educação e sua promoção envolve o enfrentamento doutrinário, político, administrativo, financeiro e organizacional, sem os quais as condições para sua efetivação não ocorrerão.

\section{Avaliação, metas de desempenho e financiamento}

Importante aspecto a ser considerado dentro da temática da responsabilidade educacional relaciona-se diretamente com a propositura de avaliações, de metas de desempenho e de financiamento da Educação.

A Lei de Diretrizes e Bases da Educação Nacional (LDB), Lei no 9.394, de 20 de dezembro de 1996 (BRASIL, 1996), já previa em seu artigo $9^{\circ}$, inciso VI, a competência da União para "[...] assegurar processo nacional de avaliação do rendimento escolar no Ensino Fundamental, médio e superior, em colaboração com os sistemas de Ensino, objetivando a definição de prioridades e a melhoria da qualidade da Educação".

Nessa temática, insere-se a regulamentação introduzida no ordenamento jurídico pátrio por meio do PNE, datado de 26 de junho de 2014, no artigo 11, normatizando o Sistema Nacional de Avaliação da Educação Básica (BRASIL, 2014).

O objetivo da regulamentação de um sistema nacional para a avaliação da Educação Básica está justamente no fornecimento de informações para que a ela ocorra e para a orientação das políticas públicas desse nível de Ensino. De modo mais preciso, só se justifica a existência de tais informações se se prestarem à orientação das políticas públicas. Assim, é imperioso concluir que as avaliações, por lei, estão direcionadas ao aperfeiçoamento e à elaboração das políticas públicas.

Igualmente, evidencia-se esse caráter democrático e republicano ao estatuir que o sistema seja operacionalizado por meio de dois indicadores. Primeiro, o indicador de rendimento escolar, referente ao desempenho dos(as) estudantes, apurado em exames nacionais de avaliação, com participação de pelo menos $80 \%$ dos (as) alunos (as) de cada ano escolar, periodicamente avaliado em cada escola, e aos dados pertinentes apurados pelo censo escolar da Educação Básica. Segundo, o indicador de avaliação institucional, relativo a características como o perfil do alunado e do corpo dos (as) 
profissionais da Educação, as relações entre dimensão do corpo docente, do corpo técnico e do corpo discente, a infraestrutura das escolas, os recursos pedagógicos disponíveis e os processos da gestão, entre outras características relevantes.

O Projeto de Lei de responsabilidade educacional, substitutivo do Relator da Comissão Especial e deputado federal Raul Henry, previu no artigo $5^{\circ}$ a utilização do Índice de Desenvolvimento da Educação Básica (Ideb) como exame nacional a ser considerado na aferição da qualidade da Educação nas redes.

Contudo, os parágrafos $1^{\circ}$ e $2^{\circ}$, do artigo 11, do PNE, afastaram textualmente a indicação do Ideb como exclusivo instrumento de avaliação da qualidade, obrigando a existência e a divulgação pormenorizada tanto dos indicadores de rendimento escolar quanto dos indicadores da avaliação institucional. $O$ texto é explícito ao apontar o alcance limitado do Ideb tão somente aos indicadores de rendimento escolar (BRASIL, 2014, inciso I, $\S 1^{\circ}$, art. 11).

Assim, os indicadores de avaliação institucional, compreendendo características como o perfil do alunado e do corpo dos (as) profissionais da Educação, as relações entre dimensão do corpo docente, do corpo técnico e do corpo discente, a infraestrutura das escolas, os recursos pedagógicos disponíveis e os processos da gestão, entre outros aspectos relevantes, não poderão estar ausentes da previsão de institucionalização de avaliação nacional por uma eventual LRE.

Esse tema foi muito bem analisado em artigo de referência, intitulado "Ideb: limites e ilusões de uma política educacional" (ALMEIDA; DALBEN; FREITAS, 2013, p. 1156):

O fator "desempenho" está associado ao aproveitamento cognitivo dos alunos, em especial em Língua Portuguesa e Matemática, e o fator "rendimento" ao fluxo escolar, determinado a partir da taxa de aprovação medida através da razão entre o tempo necessário para conclusão da etapa de escolarização e o tempo de duração efetivamente despendido para concluí-la.

A pretensão do Ideb de sumarizar a qualidade de Ensino oferecida a partir desses dois fatores não parece viável, já que incapaz de refletir a realidade das instituições, não apenas pelo que o índice deixa de considerar, em especial o NSE da população atendida, mas também pela forma como mede esses aspectos. 


\begin{abstract}
Observando-se a influência das diferenças sociais dos alunos no desempenho escolar e consequentemente no trabalho desenvolvido pela escola e sua eficácia, encontra-se nas análises de Bourdieu (1998) outro fator importante: a questão cultural. Ele evidencia que, embora o aspecto econômico seja importante para a análise da questão, há também a dimensão cultural que, como um bem capaz de favorecer o desenvolvimento dos estudantes na escola, transforma-se em um tipo de capital que pode ser mobilizado para influenciar o sucesso escolar: aspecto que chamou de "capital cultural".

Por este viés, entende-se que as diferenças socioeconômicas e culturais devem compor uma análise explicativa da diferença de desempenho dos alunos, já que não as considerar significaria, muitas vezes, atribuir o título de boa escola a instituições que, como única e verdadeira diferenciação em relação a outras, possui alunos de maior capital socioeconômico e cultural.
\end{abstract}

Decorre dessa análise que a elaboração dos índices deve contemplar o contexto em que a escola realiza seu trabalho, já que o nível socioeconômico (NSE) dos alunos é a variável que mais se relaciona com as notas, tendo a maior parte de sua variabilidade explicada pelos fatores externos à escola. Caminhou nesse sentido a previsão do artigo 11 , parágrafo $1^{\circ}$, inciso II, do PNE.

Em arremate, Almeida, Dalben e Freitas (2013, p. 1157) afirmam:

Em relação especificamente ao Ideb, nos chama a atenção a forma pela qual ele é apresentado (e divulgado) para a população, em que a escola aparece como única responsável pelo desempenho de seus alunos, sem qualquer vinculação à relação deste com seu entorno social, com a rede de Ensino à qual pertence e com as políticas públicas às quais está, direta ou indiretamente, submetida, pois tal isolamento pode gerar a ideia de que a escola e seus profissionais são, sozinhos, responsáveis pelos resultados obtidos nas avaliações externas, induzindo de forma equivocada à ideia de perda da influência do entorno social e das políticas públicas sobre os resultados dessas avaliações, tendo como consequência a desresponsabilização, de forma branda, do sistema educativo e social mais amplo sobre tais resultados.

Esse percurso é perigoso, pois acaba trazendo um movimento de responsabilização unidirecional da escola e de seus profissionais sem que a eles sejam dadas as condições objetivas de melhoria da qualidade do Ensino ofertado à população. 
Nesse diapasão, insere-se novamente o Princípio Constitucional da Eficiência aplicado ao modo de organizar, de estruturar e de disciplinar a administração pública, aqui entendida como a responsável pela Educação Básica pública.

Debruçaram-se sobre esse assunto os Projetos de Lei $\mathrm{n}^{\circ}$ 7.420/2006 (BRASIL, 2006), $\mathrm{n}^{\circ} 1.680 / 2007$ (BRASIL, 2007), $\mathrm{n}^{\circ} 413 / 2011$ (BRASIL, 2011a), $\mathrm{n}^{\circ}$ 450/2011 (BRASIL, 2011b) e $\mathrm{n}^{\circ}$ 5.519/2013 (BRASIL, 2013), assim como o mencionado projeto substitutivo. De relevo, a proposta trazida pelo Projeto de Lei n ${ }^{0} 5.519$, de 7 de maio de 2013 (BRASIL, 2013), do deputado federal Paulo Rubem Santiago, que enfatiza a criação do Sistema Nacional de Educação (SNE).

Referido Projeto de Lei fez menção expressa à regulação, à normatização, à supervisão e à avaliação dos estabelecimentos de Ensino públicos e privados, a partir de sistema nacional definido pelo PNE. Sugere no artigo $3^{\circ}, \S 5^{\circ}$, do referido Projeto de Lei, que o Sistema Nacional de Avaliação da Educação Básica seja coordenado por instância tripartite, com representação da União, dos Estados, do Distrito Federal e dos Municípios e constituirá fonte básica de informação para a avaliação da qualidade da Educação Básica e para a orientação das políticas públicas necessárias à sua melhoria e ao seu atendimento com equidade e qualidade.

Portanto, o Projeto de Lei acima citado melhor se adapta aos preceitos estabelecidos pela doutrina, pela Constituição Federal de 1988 (BRASIL, 1988), pela LDB e pelo PNE.

No tocante ao financiamento da Educação, constou da LDB, em seu artigo 74, caput, que a União, em colaboração com os Estados, o Distrito Federal e os Municípios, estabelecerá padrão mínimo de oportunidades educacionais para o Ensino Fundamental, baseado no cálculo do custo mínimo por aluno capaz de assegurar Ensino de qualidade.

Em complemento, o atual PNE trouxe importantíssimos avanços legislativos que deverão embasar a discussão de eventual LRE. A tão almejada colaboração da União com os demais entes federados está preconizada no artigo $7^{\circ}$.

$\mathrm{O}$ ato normativo em questão previu ainda a criação de uma instância permanente de negociação e de cooperação entre a União, os Estados, o Distrito Federal e os Municípios (parágrafo $5^{\circ}$ ), bem como incumbiu aos gestores federais, estaduais, municipais e do Distrito Federal a adoção das medidas governamentais necessárias ao alcance das metas previstas no PNE (parágrafo $1^{\circ}$ ). 
Para efetivação do financiamento, estabeleceu-se a Meta 20 do anexo (PNE), com o intuito de ampliar o investimento público em Educação pública de forma a atingir, no mínimo, o patamar de 7\% do produto interno bruto (PIB) do país no $5^{\circ}$ ano de vigência desta Lei e, no mínimo, o equivalente a $10 \%$ do PIB ao final do decênio.

No ponto, cabe frisar que o Custo Aluno-Qualidade (CAQ) foi referenciado como parâmetro para instrumentalizar o financiamento da Educação de todas as etapas e modalidades da Educação Básica, a partir do cálculo e do acompanhamento regular dos indicadores de gastos educacionais com investimentos em qualificação e em remuneração do pessoal docente e dos demais profissionais da Educação pública, em aquisição, em manutenção, em construção e em conservação e instalações de equipamentos necessários ao Ensino e em aquisição de material didático-escolar, alimentação e transporte escolar. Com essa preocupação, o PNE demonstra o interesse em melhorar, dentro do decênio, diversas condições estruturantes que se relacionam diretamente com a elevação do padrão mínimo de qualidade, para além do binômio professor-aluno.

Anote-se ainda a importante previsão contida na estratégia 20.10 do PNE no sentido de que "[...] caberá à União, na forma da lei, a complementação de recursos financeiros a todos os Estados, ao Distrito Federal e aos Municípios que não conseguirem atingir o valor do CAQi e, posteriormente, do CAQ" (BRASIL, 2014).

Em que pese tratar-se de norma programática, passível de ponderação com o Princípio da Reserva do Possível por parte do Poder Executivo, a previsão legal impulsiona a articulação política e econômica no sentido de se efetivar a cooperação e a complementação da União aos Estados, ao Distrito Federal e aos Municípios.

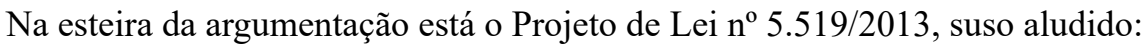

Art. $4^{\circ}$ A política de financiamento da Educação Básica, nos termos do Sistema Nacional de Educação, deverá, obrigatoriamente:

I - Amparar-se na definição do custo aluno-qualidade (CAQ), construído com a participação da sociedade civil, capaz de mensurar todos os insumos necessários à Educação de qualidade e à superação das desigualdades regionais;

II - Assegurar o investimento na valorização dos profissionais da Educação Básica, nas dimensões de: 
a) fixação de salário digno, equivalente aos profissionais de mesma formação e carreira;

b) formação inicial e continuada;

c) construção de ambiente de trabalho saudável.

Art. $5^{\circ}$ Os entes federados deverão estabelecer formas de colaboração, de forma democrática e em consonância com os planos de Educação (BRASIL, 2013).

Percebe-se que toda a construção do PNE, contida também no supracitado projeto de responsabilidade educacional, não vincula o financiamento da Educação com o atingimento de metas de desempenho. A razão, implícita nesses documentos, reside na própria fundamentalidade do direito à Educação, não permitindo retrocessos legislativos ou fático-orçamentários.

$\mathrm{O}$ (crescente) financiamento educacional não pode sofrer retrocessos por conta da existência ou criação de metas de desempenho. A vinculação, nesse particular, é medida perversa ao direito fundamental à Educação (sob pena de ferir o princípio da proibição do retrocesso).

Constou do Projeto de Lei inaugural $n^{0} 7.420 / 2006$ (BRASIL, 2006) a vinculação das transferências voluntárias da União à comprovação de esforços efetivamente realizados e às melhorias de desempenho efetivamente evidenciadas pelo processo de avaliação nacional (artigo $3^{\circ}$ ), com previsão de suspensão das transferências voluntárias da União ao Estado ou ao Município, caso haja descumprimento do disposto no projeto $\left(\operatorname{artigo} 5^{\circ}\right)$.

O Relator da Comissão Especial, no tópico relacionado com a constitucionalidade, juridicidade e adequação orçamentária e financeira, apresentou a ressalva em relação ao aspecto orçamentário e financeiro para afastar os artigos dos Projetos de Lei $\mathrm{n}^{\circ}$ 7.420/2006, $\mathrm{n}^{\circ}$ 1.680/2007 (BRASIL, 2007), $\mathrm{n}^{\circ}$ 413/2011 (BRASIL, 2011a) e $n^{\circ} 450 / 2011$ (BRASIL, 2011b) no tocante à penalidade de suspensão de transferências voluntárias da União, voltadas para a Educação, aos entes federados que não cumprirem as disposições previstas nas normas propostas:

Há, portanto, um dispositivo de lei complementar que busca salvaguardar, entre outros, o setor educacional dessa penalização como decorrência da inadequada gestão fiscal dos entes federados. 
Esse espírito legal leva a ponderar a conveniência de adotar sanção dessa natureza no âmbito da própria legislação educacional. Por isso mesmo, o Substitutivo a seguir apresentado não considera essa possibilidade (BRASIL, 2006).

O veto embasou-se na Lei Complementar $\mathrm{n}^{\circ}$ 101, de 4 de maio de 2000 (Lei de Responsabilidade Fiscal [BRASIL, 2000]), que excepciona no artigo 25, parágrafo $3^{\circ}$, a suspensão das transferências voluntárias para as ações na área de Educação, de saúde e de assistência social, no caso de não cumprimento das exigências prescritas no parágrafo $1^{\circ}$ do mesmo artigo.

A não acolhida da referida penalização está em total consonância com a garantia, a promoção e a proteção do direito fundamental à Educação Básica pública, merecendo registro. A previsão de suspensão das transferências voluntárias macula diretamente o direito fundamental à Educação, obstaculizando todo o processo de ampliação deste direito e influindo negativamente nas conquistas políticas, sociais e jurídicas.

Com sensibilidade, Ximenes (2012, p. 358, grifo nosso) chama a atenção para esta incongruente proposta:

Se algumas das medidas previstas podem parecer interessantes, principalmente a previsão de elevação do gasto por aluno, outras acabam punindo duplamente a coletividade, e não exatamente os responsáveis, como fica evidente na hipótese de suspensão das transferências voluntárias aos entes federados que não alcancem as metas acadêmicas ou não respeitem as demais disposições.

A mens legis objetivou proteger os direitos fundamentais da Educação, da saúde e da assistência social, ainda que os ocupantes dos cargos públicos não desempenhem a contento, em algum momento histórico, a função administrativa. Agiu bem o legislador ao estabelecer essa salvaguarda, bem como o relator da Comissão Especial, ao afastar do Substitutivo tal previsão encontrada, equivocadamente, naqueles Projetos de Lei.

De todo modo, possível Projeto de Lei deve debruçar-se sobre as hipóteses de financiamento e de promoção da Educação, sem vinculação a metas de desempenho focadas exclusivamente no rendimento escolar, como esboçado no PNE e no Projeto de Lei ${ }^{\circ}$ 5.519/2013 (BRASIL, 2013). 


\section{Responsabilização dos agentes públicos}

De início, oportuno se faz referir a existência de diversas formas de responsabilidade dos agentes públicos e colaboradores da Administração Pública, merecendo menção as previsões no plano administrativo e cível: Constituição Federal de 1988 (BRASIL, 1988), Código Civil (BRASIL, 2002), LDB (BRASIL, 1996) e Estatuto da Criança e do Adolescente (BRASIL, 1990), Lei da Ação Civil Pública (ACP) (BRASIL, 1985), dentre outros.

Nos casos de descumprimento de obrigações, a ACP tem sido utilizada em larga escala para a efetivação do direito fundamental à Educação, com respaldo judiciário, impondo algumas obrigações de fazer, notadamente quanto ao acesso e condições no Ensino público fundamental, e mais recentemente à Educação infantil pública.

Considerando a gama de legislação relacionada com punibilidade dos agentes públicos, o Projeto de Lei $\mathrm{n}^{\mathrm{o}}$ 7.420/2006 (BRASIL, 2006) ${ }^{1}$ remetia a responsabilização pela infração político-administrativa e pelo ato de improbidade administrativa às correlatas legislações, apenas prevendo a aplicação de pena de multa ou com prazo definido em dobro.

A proposta substitutiva apresentada pelo relator Raul Henry prende-se às obrigações exigíveis por meio da ACP, acolhendo a proposta da bancada governista da época (Projeto de Lei $\mathrm{n}^{\circ} 8.039$, de 21 de dezembro de 2010 [BRASIL, 2010]) para especificar a criação de uma "Ação Civil Pública Educacional”.

A previsão de responsabilização reforça a ideia punitiva, em contraposição à proposta de promoção, posto que qualquer desvio de conduta do agente público encarregado de garantir uma Educação Básica pública com padrão de qualidade sempre foi passível de responsabilização administrativa, civil, política e penal.

Do exposto, o projeto substitutivo encampou a ênfase no caráter sancionatório, ainda que por meio da adoção da responsabilidade genuinamente civil, através da tipificada ação civil pública.

\footnotetext{
Projeto de Lei $n^{\circ} 7.420 / 2006$ : Art. $4^{\circ}$ O descumprimento do disposto nesta Lei caracteriza-se como: I - crime de responsabilidade por violação patente contra o exercício de direitos individuais e sociais, nos termos do art. $7^{\circ}$, número 9, da Lei $n^{\circ} 1.079$, de 10 de abril de 1950;

II - infração político-administrativa por deixar de defender direitos e interesses do Município, nos termos do art. $4^{\circ}$, VIII, do Decreto-lei $n^{\circ} 201$, de 27 de fevereiro de 1967 .

III - ato de improbidade administrativa, especialmente nos termos do art. 11, II, da Lei $\mathrm{n}^{\circ} 8.429$, de 2 de junho de 1992.

Parágrafo único. Na hipótese de infrações sujeitas a penalidades de multa ou com prazo definido, os valores e prazos serão aplicados em dobro em relação ao estabelecido na respectiva legislação.
} 
A promoção da Educação Básica pública com padrão mínimo de qualidade merece a adoção de medidas de financiamento, infraestrutura, cooperação técnica e gestão democrática, tendo nestes pilares os esteios de uma mudança estrutural no panorama educacional, afastando-se a motivação do desempenho em virtude de eventual responsabilização.

É pensando na promoção da Educação que se espera uma legislação sobre responsabilidade educacional que reconheça o modo de organizar, estruturar e disciplinar a Administração Pública voltada para o foco da eficiência na prestação do serviço público. É responsabilidade de própria Administração Pública prover a organização e a estrutura elementar para a garantia de um padrão mínimo de qualidade da Educação Básica pública.

Em consonância com o dito acima, o PNE não vincula o financiamento da Educação com o atingimento de metas de desempenho. A razão reside na própria fundamentalidade do direito à Educação, não permitindo retrocessos legislativos ou fático-orçamentários. Assim, é forçoso reconhecer que a perspectiva de um crescente financiamento educacional não pode sofrer retrocessos por conta da existência ou criação de metas de desempenho. A vinculação, como dito, é medida perversa ao direito fundamental à Educação - sob pena de ferir o princípio da proibição do retrocesso.

\section{Considerações finais}

No contexto atual, em que direitos educativos estão ameaçados, é extremamente provável que propostas de uma eventual LRE sejam apresentadas por parlamentares conservadores, com forte viés punitivista.

Noutro giro, ainda que a análise aqui realizada de Projetos de Lei de Responsabilidade Educacional (LRE) aponte eventuais prejuízos ou riscos destes à qualidade da Educação, deve ficar claro que tais prejuízos não podem, em hipótese alguma, ser colocados no mesmo patamar de ameaças à qualidade da Educação de alguns outros projetos como, por exemplo, a discussão altamente ideológica do Movimento "Escola Sem Partido". De fato, este último projeto está claramente voltado ao interesse de determinadas classes de se apropriarem do Estado e do sistema de Ensino formal e, a posteriori, delinearem os currículos das escolas, os conteúdos a serem ensinados, com o objetivo de construir um consenso social com uma orientação específica (CAPAVERDE; LESSA; LOPES; 2019) e de instaurar uma visão de mundo escolar apoiada em esquemas binários e convencionais de pensamento (SANTOS; CERVI; 2019). Ressalte-se ainda que as iniciativas de 
aprovação na legislação estadual e municipal sobre a "Escola Sem Partido" foram consideradas inconstitucionais pelo Supremo Tribunal Federal (STF).

Neste quadro, é essencial que as forças democráticas estejam atentas e alertem a sociedade sobre os efeitos nefastos que adviriam de uma eventual LRE com esta perspectiva. Cabe também mostrar que tal lei deve estar em consonância com o espírito que anima o PNE, qual seja, a formação de um sistema nacional de Educação participativo e democrático, capaz de assegurar os direitos educacionais de toda a população brasileira, através de mecanismos também participativos e democráticos.

Diante disso, espera-se que eventual LRE atenha-se em articular elementos políticos, financeiros, administrativos, tecnológicos, organizacionais e pedagógicos para a promoção da Educação Básica pública com padrão mínimo de qualidade, afastando-se da ênfase punitiva como vetor de transformação.

A qualidade almejada virá da promoção da Educação e é nesse sentido que o PNE aponta. 


\title{
Whose responsibility? An analysis of the perspectives for the educational responsibility law, foreword in the National Education Plan
}

\begin{abstract}
The promotion of a minimum standard of quality for public basic education should be the main goal for the elaboration of the legislation on educational responsibility, contemplating the way of organizing, structuring and disciplining the Public Administration, aimed at the achievement of efficiency in the provision of the public service. The National Education Plan (PNE) does not link the financing of education with the attainment of performance targets, due to the very fundamental right to education, not allowing legislative or factico-budgetary backsliding. Therefore, an eventual Educational Responsibility Law (LRE) should focus on articulating political, financial, administrative, technological, organizational and pedagogical elements for the promotion of public basic education with a minimum standard of quality, moving away from the punitive emphasis as a vector of transformation.
\end{abstract}

Keywords: Educational Policy. Law of Educational Responsibility. National Education Plan.

\section{¿De quienes es la responsabilidad? Un análisis de las perspectivas para la ley de responsabilidad educativa propuesta en el Plan Nacional de Educación}

\section{Resumen}

La promoción de un estándar mínimo de calidad para la educación básica pública orientará la elaboración de la legislación sobre responsabilidad educativa, contemplando la forma de organizar, estructurar y disciplinar la Administración Pública, con el objetivo de lograr la eficiencia en la prestación del servicio público. El Plan Nacional de Educación (PNE) no vincula su financiamiento al logro de metas de desempeño, por la propia fundamentalidad del derecho a la Educación, no permitiendo retrocesos legislativos o fácticos-presupuestarios. Por lo tanto, la posible Ley de Responsabilidad Educativa (LRE) debe, sobre todo, enfocarse en articular elementos politicos, financieros, administrativos, tecnológicos, organizativos y pedagógicos para la promoción de la educación básica pública con un estándar mínimo de calidad, alejándose del énfasis punitivo como un vector de transformación.

Palabras clave: Política educativa. Ley de Responsabilidad Educativa. Plan Nacional de Educación. 


\section{Referências}

ALMEIDA, L. C.; DALBEN, A.; FREITAS, L. C. O IDEB: limites e ilusões de uma política educacional. Educação \& Sociedade, Campinas, v. 34, n. 125, p. 1153-1174, out./dez. 2013. https://doi.org/10.1590/S0101-73302013000400008

BRASIL. Lei ${ }^{\circ} 7.347$, de 24 de julho de 1985. Disciplina a ação civil pública de responsabilidade por danos causados ao meio-ambiente, ao consumidor, a bens e direitos de valor artístico, estético, histórico,turístico e paisagístico (VETADO) e dá outras providências. Diário Oficial da União, Brasília, DF, 25 jul. 1985.

BRASIL. Lei n ${ }^{\circ} 9.394$, de 20 de dezembro de 1996. Estabelece as diretrizes e bases da educação nacional. Diário Oficial da União, Brasília, DF, 23 dez. 1996.

BRASIL. Lei $\mathrm{n}^{\mathrm{o}}$ 13.005, de 25 de junho de 2014. Aprova o Plano Nacional de Educação - PNE e dá outras providências. Diário Oficial da União, Brasília, DF, 26 jun. 2014.

BRASIL. Lei Complementar $\mathrm{n}^{\mathrm{o}}$ 101, de 4 de maio de 2000. Estabelece normas de finanças públicas voltadas para a responsabilidade na gestão fiscal e dá outras providências. Diário Oficial da União, Brasília, DF, 5 maio 2000.

BRASIL. Lei n ${ }^{\circ} 10.406$, de 10 de janeiro de 2002. Institui o Código Civil. Diário Oficial da União, Brasília, DF, 11 jan. 2002.

BRASIL. Lei 8.069, de 13 de julho de 1990. Brasília, DF, 1990. Dispõe sobre o Estatuto da Criança e do Adolescente e dá outras providências. Diário Oficial da União, Brasília, DF, 16 jul. 1990.

BRASIL. Câmara dos Deputados. Projeto de Lei $n^{\circ} 5.519$, de 7 de maio de 2013. Institui o Sistema Nacional de Educação. Disponível em: https://www. camara.leg.br/proposicoesWeb/fichadetramitacao?idProposicao $=575890$. Acesso em: 6 nov. 2014.

BRASIL. Câmara dos Deputados. Projeto de Lei $n^{\circ} 7.420$, de 9 de agosto de 2006. Dispõe sobre a qualidade da Educação Básica e a responsabilidade dos gestores públicos na sua promoção. Disponível em: https://www.camara.leg.br/ proposicoesWeb/fichadetramitacao?idProposicao=332457. Acesso em: 6 nov. 2014.

BRASIL. Câmara dos Deputados. Projeto de Lei $n^{\circ} 1.680$, de 2 de agosto de 2007. Dispõe sobre a qualidade da Educação Básica e a responsabilidade dos gestores públicos na sua promoção. Disponível em: 
https://www.camara.leg.br/proposicoesWeb/fichadetramitacao?idProposic ao=361093. Acesso em: 12 maio 2021.

BRASIL. Câmara dos Deputados. Projeto de Lei $n^{\circ} 413$, de 15 de fevereiro de 2011a. Dispõe sobre a qualidade da Educação Básica e a responsabilidade dos gestores públicos na sua promoção. Disponível em: https://www.camara.leg. $\mathrm{br} /$ proposicoesWeb/fichadetramitacao?idProposicao=492039. Acesso em: 12 maio 2021.

BRASIL. Câmara dos Deputados. Projeto de Lei no 450, de 16 de fevereiro de 2011b. Dispõe sobre a qualidade da Educação Básica e a responsabilidade dos gestores públicos na sua promoção. Disponível em: https://www.camara.leg. $\mathrm{br} /$ proposicoesWeb/fichadetramitacao?idProposicao=492235. Acesso em: 12 maio 2021.

BRASIL. Câmara dos Deputados. Projeto de Lei $n^{\circ} 8.039$, de 21 de dezembro de 2010. Altera a Lei $\mathrm{n}^{\circ} 7.347$, de 24 de julho de 1985, para disciplinar a ação civil pública de responsabilidade educacional, e dá outras providências. Disponível em: http://www.camara.gov.br/proposicoesweb/fichadetramitacao? idproposicao=490172. Acesso em: 06 nov. 2014.

BRASIL. Senado Federal. Constituição da República Federativa do Brasil. Brasília, DF, 1988.

CAPAVERDE, C. B.; LESSA, B. S.; LOPES, F. D. "Escola sem Partido" para quem? Ensaio: Avaliação e Políticas Públicas em Educação, Rio de Janeiro, v. 27, n. 102, p. 204-222, mar. 2019. https://doi.org/10.1590/s0104-40362018002601369

CURY, C. R. J. Lei de responsabilidade educacional. Direito e Sociedade: Revista de Estudos Jurídicos e Interdisciplinares, Catanduva, v. 7, n. 1, p. 9-18, jan./dez. 2012. Disponível em: http://fundacaopadrealbino.org.br/ facfipa/ner/pdf/ed07dirpsite.pdf\#page=10. Acesso em: 13 set. 2018.

DI PIETRO, M. S. Z. Direito administrativo. 22. ed. São Paulo: Atlas, 2009.

DINIZ, H. D. M.; FONTANIVE, N. S.; KLEIN, R. Indicadores de qualidade na educação básica. In: ASSOCIAÇÃO BRASILEIRA DE MAGISTRADOS, PROMOTORES DE JUSTIÇA E DEFENSORES PÚBLICOS DA INFÂNCIA E DA JUVENTUDE. Todos pela Educação (org.). Justiça pela qualidade na Educação. São Paulo: Saraiva, 2013. p. 537-571. 
FREITAS, L. C. Lei de responsabilidade educacional? ComCiência, Campinas, n. 132, 2011. Disponível em: http://comciencia.scielo.br/scielo. php?script-sci_arttext\&pid=S1519-76542011000800009\&lng=en\&nrm=iso. Acesso em: 9 out. 2013.

GOMES, C. A. Fundamentos de uma lei de responsabilidade educacional. Brasília, DF: Unesco, 2008. (Série Debates, v. 10).

LEITE, Y. U. F.; DI GIORGI, C. A. G. Qualidade na e da escola pública. Campo Grande: UCDB, 1995. (Série Estudos).

OLIVEIRA, R. P.; ARAÚJO, G. C. Qualidade do ensino: uma nova dimensão da luta pelo direito à Educação. Revista Brasileira de Educação, Rio de Janeiro, n. 28, p. 5-23, jan./abr. 2005. https://doi.org/10.1590/S1413-24782005000100002

PARO, V. H. Gestão escolar, democracia e qualidade do ensino. São Paulo: Ática, 2007.

SANTOS, T. R.; CERVI, G. M. D. Quixote contra os moinhos: um ensaio sobre o Movimento Escola Sem Partido. Ensaio: Avaliação e Políticas Públicas em Educação, Rio de Janeiro, v. 27, n. 105, p. 712-731, dez. 2019. https://doi.org/10.1590/s0104-40362019002701549

XIMENES, S. B. Responsabilidade educacional: concepções diferentes e riscos iminentes ao direito à Educação. Educação \& Sociedade, Campinas, v. 33, n. 119, p. 353-377, 2012. https://doi.org/10.1590/S0101-73302012000200003

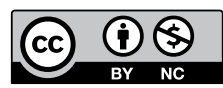

\section{Informações sobre os autores}

Danilo Trombetta Neves: Mestre em Educação pela Universidade Estadual Paulista. Procurador Federal na Procuradoria Geral Federal - Advocacia Geral da União. Contato: danilotn@hotmail.com

iD https://orcid.org/0000-0001-9863-1713

Cristiano Amaral Garboggini Di Giorigi: Pós-Doutorado e Doutorado em Educação pela Universidade de São Paulo. Professor Titular aposentado da Universidade Estadual Paulista. Professor do Programa de Pós-Graduação em Educação da Universidade do Oeste Paulista. Contato: utopico92@gmail.com

(iD) https://orcid.org/0000-0002-3977-3217 